\title{
PEMANFAATAN FILM PENDEK DOKUMENTER SEBAGAI MEDIA EDUKASI PELESTARIAN KURA-KURA CUORA AMBOINENSIS
}

\author{
Godham Eko Saputro ${ }^{1}$, Toto Haryadi ${ }^{2}$ \\ 1,2Fakultas IImu Komputer Universitas Dian Nuswantoro \\ Jalan Imam Bonjol No. 207 Semarang, 50131 \\ godham.eko@gmail.com ${ }^{1}$, toto.haryadi@dsn.dinus.ac.id ${ }^{2}$
}

\begin{abstract}
Abstrak: Cuora Amboinensis atau kura-kura ambon merupakan salah satu hewan liar berstatus Appendix II, yaitu hewan yang akan punah jika terus dieksploitasi. Persoalan yang terjadi yaitu kurangnya pengetahuan cara melestarikan dan mengembangbiakkan kura-kura ini secara tepat. Hal ini salah satunya disebabkan masih sedikitnya media edukasi yang menyajikan informasi tersebut. Di sisi lain, perkembangan media digital dan sosial seperti Youtube memiliki potensi luar biasa yang belum banyak tersentuh. Dari permasalahan tersebut dibutuhkan media edukatif yang memberikan informasi secara nyata, efektif, dan persuasif, salah satunya yaitu film pendek dokumenter. Penelitian dilakukan menggunakan metode kualitatif yang fokus pada cara hidup, habitat yang tepat, serta proses berkembang biak Cuora Amboinensis. Data tentang hewan tersebut diperoleh dengan wawancara, observasi, studi literatur, serta pengalaman pribadi yang kemudian dianalisis menggunakan metode framing serta dijadikan sebagai dasar untuk perancangan film pendek dokumenter melalui tahapan praproduksi, produksi, dan pascaproduksi. Hasil penelitian yaitu media audio visual edukatif yang bisa dipublikasikan melalui media digital Youtube sehingga mudah diakses dan ditonton oleh banyak orang di seluruh wilayah. Penelitian ini bisa dikembangkan lebih lanjut dalam mendukung upaya pemerintah untuk melestarikan lingkungan maupun satwa liar di Indonesia.

Kata kunci: Cuora Amboinensis, media edukasi, film pendek, dokumenter
\end{abstract}

Abstract: Cuora Amboinensis, known as Kura Ambon, is one of wild animals with Appendix Il status, which indicates the animal will be extinct if it continues be exploited. The problem that occurs is the lack of knowledge on how to conserve and breed these turtles properly. This is partly due to the lack of educational media presenting this information. On the other hand, the advance of digital and social media such as Youtube have good potential which is seldom to be explored. From these problems, we need the media which can serve real, effective, and persuasive information in the form of a short documentary film. This research uses qualitative 
method which focuses about the life, habitat, and breed process of Cuora Amboinensis. The data is obtained through interview, observation, literature, and personal experience, analyzed using framing method and it is also used to design shot documentary film through pre-production, production, and post-production steps. The result of this research is an educational audio-visual media which can be published on Youtube so it will be easy to be accessed and viewed by many people in all regions. This research can be developed further to support the government program about conservation of environment and animals in Indonesia.

Keywords:Cuora Amboinensis, educational media, short film, documenter

\section{PENDAHULUAN}

Cuora Amboinensis atau yang lebih dikenal dengan kura-kura ambon merupakan salah satu spesies satwa liar kura-kura lokal endemik Indonesia yang bersifat semi aquatic, yaitu memiliki kemampuan hidup di air dan di darat (Megumi, 2020). Keberadaan populasinya yang semakin menyusut akibat perubahan iklim, rusaknya habitat asli, serta penangkapan besarbesaran membuat kura-kura ini berada pada Appendix // berdasarkan IUCN dan CITES (Septian, 2017). Status Cuora Ambionensis menjadi spesies yang akan segera punah jika terus dieksploitasi. Hingga kini, upaya telah dilakukan oleh Balai Konservasi Sumber Daya Alam (BKSDA) agar tetap terjaga kelestarian dan keseimbangan populasinya yaitu dengan mengadakan kegiatan pelepasan satwa liar.

Pasal 21 ayat 2 dalam Undang - Undang Nomor 5 Tahun 1990 tentang Konservasi Sumber Daya Alam dan Ekosistemnya menegaskan bahwa setiap orang dilarang untuk memelihara, memperniagakan, atau membunuh satwa yang dilindungi. Tetapi alasan mengapa kura jenis ini masih leluasa ditemukan di pasar ikan, pet shop, atau situs jual beli online, dikarenakan kura tersebut didapatkan dari hasil penangkaran, bukan diambil dari alam. Dengan kata lain, memelihara reptil langka atau dilindungi masih menjadi kegiatan legal. 
Berdasarkan observasi penulis, Cuora Amboinensis memiliki kelebihan yaitu mudah dikembangbiakkan karena perawatan dan penyediaan pakan tidak rumit. Hal ini sebenarnya bisa menjadi peluang untuk mendukung program kelas konservasi satwa BKSDA, yang bertujuan untuk memperkenalkan beberapa jenis reptil dan burung yang dilindungi. Di sisi lain, upaya masyarakat dalam memelihara dan mengembangbiakkan Cuora Amboinensis tidak diikuti dengan pengetahuan yang memadai khususnya terkait penyediaan habitat, cara merawat, serta teknik pengembangbiakan yang tepat. Beberapa tindakan yang tidak tepat seperti menggunakan ember atau baskom sebagai habitat, tidak menyiapkan medium pasir untuk tempat bertelur, tidak menyediakan kolam sebagai tempat berendam, tidak memberi makan secara teratur, serta tidak melihat dan membersihkan tempat maupun kura-kura secara berkala. Contoh tersebut bisa menghambat pelestarian Cuora Amboinensis.

Berdasarkan aktivitas studi literatur yang telah dilakukan penulis, penelitian yang membahas tentang Cuora Amboinensis lebih fokus pada penjelasan morfologi pertumbuhan fisiknya dan habitat tempat hidupnya. Hal ini sebagaimana dilakukan untuk mempelajari pertumbuhan awal Cuora Amboinensis sebagai sarana belajar tentang zoologi vertebrata (Maryani et al., 2018). Observasi juga dilakukan penulis pada media digital salah satunya Youtube, yang mana cukup banyak video yang menyajikan informasi tentang Cuora Amboinensis. Namun, informasi yang tersaji pada media tersebut lebih didasarkan pada pengalaman pribadi. Hal ini menjadi perhatian penulis, karena upaya memelihara dan mengembangbiakkan Cuora Amboinensis dengan benar dan tepat dengan mempertimbangkan pendapat dari ahli atau pakar Cuora Amboinensis perlu menjadi perhatian utama.

Ketersediaan media yang melimpah di era Internet of Thing (IoT) seharusnya bisa dimanfaatkan untuk mengatasi permasalahan di atas karena 
pada dasarnya media berperan penting dalam memberi informasi, mengubah opini publik dan memberi hiburan, serta yang utama yaitu mengedukasi (Sambo, 2019:38). Namun, perkembangan media digital atau media sosial yang sangat pesat justru belum bisa dimanfaatkan secara maksimal mengingat berdasarkan studi Nielsen tahun 2018 menunjukkan terdapat potensi yang sangat besar bahwa masyarakat Indonesia setiap hari menghabiskan waktu rata-rata 4 jam 53 menit untuk menonton televisi dan 3 jam 14 menit untuk mengakses internet (Fajar, 2019).

Penggunaan media sosial untuk gerakan pelestarian lingkungan termasuk pelestarian dan pengembangbiakan hewan liar, dalam waktu singkat dapat dimanfaatkan untuk menghimpun banyak dukungan pengguna sosial dan gerakan sosial yang bertujuan untuk kepentingan non-ekonomis serta bukan hanya sekedar click activism (Kapriani dan Lubis, 2014:161). Salah satunya yaitu media Youtube, yang memiliki kemampuan menyajikan informasi edukasi berbasis audio visual dan telah menarik perhatian dunia periklanan, politik, pendidikan, serta hiburan. Hal ini didukung oleh kemampuan indera mata manusia yang mampu menangkap pesan visual sebesar $83 \%$ dan indera telinga mampu menangkap pesan audio $11 \%$ (Tabrani, 2005:51). Media berbasis audio visual berpotensi efektif mengingat targetnya adalah kelompok milenial yang terbiasa menggunakan smartphone untuk berselancar di dunia maya.

Media digital dan Youtube memiliki potensi melahirkan proses penyebaran gagasan dan pengetahuan yang sangat luas secara masif tanpa khawatir terhadap batasan ruang dan waktu, di sisi lain juga bisa menjadi bumerang jika tidak digunakan sebagai mestinya atau untuk menyebar konten-konten negatif (Rahmawan, Mahameruaji, 2018:84). Adaptasi Youtube sebagai media edukasi sangat potensial karena beberapa tahun terakhir konten media digital dalam bentuk video sedang menjamur dan 
banyak digemari (Nielsen, 2016). Sumber informasi yang bisa dicari dari Youtube sangat beraneka ragam seperti referensi untuk acara TV, berita terkini, berita sejarah, video tematik, video ensiklopedia, hingga film dokumenter yang profesional maupun amatir (Faiqah, Najib and Amir, 2016:262).

Sebagai bagian dari audio visual, film dokumenter menyajikan suatu peristiwa atau kejadian secara hidup (vivid) apa adanya sesuai realita sehingga diharapkan mampu mempengaruhi pikiran dan perasaan audiens (Topatimasang, Rahardjo and Fakih, 2015:134). Penggunaan film dokumenter saat ini masih didominasi oleh dunia pendidikan, politik, budaya, dan kesehatan, namun untuk pelestarian hewan liar masih sangat sedikit konten yang bisa ditemukan dan hanya diproduksi oleh lembaga berskala besar seperti National Geographic dan Discovery Channel.

Selain itu, faktor konsep dan teknis juga menjadi alasan media edukasi dalam bentuk film dokumenter tidak sebanyak media edukasi yang disajikan melalui infografis/ poster digital. Khususnya film pendek dokumenter yang durasinya kurang dari 60 menit, yang mana harus bisa menyajikan pesan secara padat dalam waktu yang singkat, serta biaya yang harus dikeluarkan secara mandiri dalam proses pembuatannya (Mabruri, 2013:6). Meskipun secara teknis butuh kemampuan yang tinggi dan kompleks, upaya pelestarian lingkungan maupun hewan liar melalui film dokumenter mulai diapresiasi oleh pihak pemerintah, perusahaan, hingga masyarakat. Salah satunya adalah film Pohon yang diproduksi tahun 2020, para sineas muda mendapatkan penghargaan karena mengangkat tema peduli lingkungan, yakni "Hutan Rusak, Bencana Merangsak" (Rahmad, 2020).

Berdasarkan permasalahan di atas tentang kurangnya pengetahuan yang benar tentang upaya pelestarian dan pengembangbiakan Cuora Amboinensis serta peluang untuk ikut berpartisipasi dalam melestarikan 
hewan liar dari kepunahan, maka dibutuhkan media yang memiliki unsur kebaruan berupa edukasi film pendek dokumenter berbasis audio visual yang akan disajikan melalui media digital khususnya platform Youtube. Pemanfaatan ini diharapkan memiliki dapat memberikan informasi kepada masyarakat akan pentingnya menjaga keanekaragaman hayati agar kehidupan di muka bumi ini tetap lestari. Kontribusi keilmuan desain komunikasi visual pun mampu mewujudkan karya kreatif dengan pesan yang mampu tersampaikan dengan baik.

\section{METODE PENELITIAN}

Penelitian pemanfaatan film pendek dokumenter sebagai media edukasi pelestarian Cuora Amboinensis menggunakan metode kualitatif, yaitu metode yang bersifat multidisiplin, menggali subjek yang akan diteliti, serta melibatkan interpretasi dalam konteks latar yang alamiah (Creswell, 1998). Metode ini digunakan untuk menggali data dengan berbagai pendekatan empiris seperti: studi kasus, pengalaman pribadi, wawancara, observasi, teks visual, interaksi, dan sebagainya (Resmadi, Bastari and Prahara, 2020:217218). Penelitian ini difokuskan pada Cuora Amboinensis untuk dipelajari tentang identitas secara umum, cara hidup, habitat yang tepat, serta upayaupaya yang perlu dilakukan untuk menjaga kelestariannya. Pengumpulan data dilakukan dengan metode wawancara kepada pakar kura-kura di Semarang, observasi, studi literatur, serta pengalaman penulis dalam melestarikan hewan ini.

Data yang telah diperoleh dianalisis menggunakan framing, yaitu membingkai masalah menjadi realita-realita, membandingkan dengan kondisi ideal, mencari penyebabnya, serta merumuskan statement sebagai kesimpulan akhir dari pokok masalah yang diangkat (Saputro and Haryadi, 
2018:98). Berikut analisis framing yang telah dirumuskan terkait permasalahan seputar pelestarian Cuora Amboinensis.

Tabel 1 Analisis framing masalah pelestarian Cuora Amboinensis

\begin{tabular}{|c|c|c|c|c|}
\hline No. & Realita & Ideal & Penyebab & Statement \\
\hline 1 & $\begin{array}{l}\text { Masyarakat } \\
\text { khususnya } \\
\text { milenial } \\
\text { memelihara } \\
\text { Cuora } \\
\text { Amboinensis } \\
\text { dengan cara } \\
\text { yang berbeda- } \\
\text { beda }\end{array}$ & $\begin{array}{l}\text { Upaya pemeliharaan } \\
\text { untuk menjaga } \\
\text { kelestarian sesuai } \\
\text { dengan instruksi dan } \\
\text { anjuran pakar atau ahli } \\
\text { kura-kura }\end{array}$ & $\begin{array}{l}\text { Upaya } \\
\text { pemeliharaan } \\
\text { Cuora } \\
\text { Amboinensis } \\
\text { sifatnya amatir } \\
\text { (hobi) }\end{array}$ & $\begin{array}{l}\text { Upaya inisiatif dalam } \\
\text { memelihara Cuora } \\
\text { Amboinensis perlu } \\
\text { dilakukan secara } \\
\text { serius sebagai bentuk } \\
\text { ikut membantu } \\
\text { program pelestarian } \\
\text { hewan ini }\end{array}$ \\
\hline 2. & $\begin{array}{l}\text { Penelitian } \\
\text { tentang Cuora } \\
\text { Amboinensis } \\
\text { saat ini lebih } \\
\text { banyak untuk } \\
\text { kepentingan } \\
\text { edukasi / } \\
\text { pendidikan } \\
\text { sekolah }\end{array}$ & $\begin{array}{l}\text { Penelitian tentang Cuora } \\
\text { Amboinensis } \\
\text { dikomunikasikan tidak } \\
\text { hanya kepada pelajar } \\
\text { saja, tetapi juga } \\
\text { masyarakat luas } \\
\text { khususnya kelompok } \\
\text { milenial yang tertarik } \\
\text { terhadap isu-isu } \\
\text { lingkungan }\end{array}$ & $\begin{array}{l}\text { Masyarakat } \\
\text { khususnya } \\
\text { kelompok } \\
\text { milenial belum } \\
\text { dilibatkan } \\
\text { untuk upaya } \\
\text { serius semacam } \\
\text { ini }\end{array}$ & $\begin{array}{l}\text { Libatkan masyarakat } \\
\text { sekitar khususnya } \\
\text { milenial untuk turut } \\
\text { melestarikan Cuora } \\
\text { Amboinensis sehingga } \\
\text { memperoleh } \\
\text { informasi yang } \\
\text { memadai }\end{array}$ \\
\hline 3. & $\begin{array}{l}\text { Masih sedikit } \\
\text { penelitian cara } \\
\text { pelestarian } \\
\text { Cuora } \\
\text { Amboinensis } \\
\text { yang } \\
\text { melibatkan } \\
\text { media digital } \\
\text { yang sesuai } \\
\text { dengan milenial }\end{array}$ & $\begin{array}{l}\text { Penelitian Cuora } \\
\text { Amboinensis tidak hanya } \\
\text { dalam bentuk paper } \\
\text { ilmiah, tetapi juga } \\
\text { melalui media lain yang } \\
\text { sesuai dengan kondisi } \\
\text { dan situasi milenial saat } \\
\text { ini }\end{array}$ & $\begin{array}{l}\text { Media } \\
\text { komunikasi } \\
\text { yang dianggap } \\
\text { kredibel saat ini } \\
\text { masih berupa } \\
\text { karya ilmiah } \\
\text { hasil penelitian }\end{array}$ & $\begin{array}{l}\text { Sajikan media digital } \\
\text { yang mudah } \\
\text { dipahami, bisa dishare } \\
\text { secara luas dengan } \\
\text { model cerita berbagi } \\
\text { pengalaman (dan } \\
\text { tidak menggurui) } \\
\text { dalam pelestarian } \\
\text { Cuora Amboinensis }\end{array}$ \\
\hline
\end{tabular}
Sumber: Saputro dan Haryadi, 2020

Berdasarkan analisis framing di atas, untuk melestarikan dan mengembangbiakkan Cuora Amboinensis tidak sekedar hanya fokus pada medianya saja, tetapi juga peran serta milenial dalam upaya tersebut. Pengemasan pesan perlu mempertimbangkan karakter milenial yang antusias, aktif, mau mempelajari sesuatu, tidak mau disuruh, serta tidak mau digurui, sehingga dengan mempertimbangkan hal-hal tersebut, maka dibutuhkan komunikasi berbasis media digital yang bisa memberi informasi 
aktual, sesuai dengan fakta di lapangan, serta tidak terkesan menggurui sehingga dengan sendirinya bisa menarik minat milenial untuk turut serta dalam memelihara Cuora Amboinensis bukan sekedar hobi, tetapi juga ikut melestarikannya sebagai program dari pemerintah demi kelestarian hewan ini kedepannya. Salah satu caranya yaitu melalui media audio visual berwujud film pendek dokumenter sebagai luaran penelitian ini. Penulis menggunakan metode perancangan film dokumenter yang terdiri dari tiga tahap, yaitu: praproduksi yang fokus pada persiapan pembuatan film pendek seperti pengumpulan bahan/data untuk konten film dan pembuatan storyboard; produksi yang fokus pada perekaman video; serta pasca produksi yang fokus pada editing, rendering, dan publish (Perkasa and Sayatman, 2015:359).

\section{HASIL DAN DISKUSI}

\section{Tahap Praproduksi}

Tahap praproduksi fokus pada upaya perencanaan pembuatan film pendek dokumenter sebagai media pemeliharaan dan pelestarian Cuora Amboinensis yang sesuai dengan target audiens kelompok milenial. Pada tahap ini diawali dengan proses brainstorming mulai dari penentuan cara menyajikan pesan yang serius namun santai agar bisa diterima oleh audiens, pesan apa saja yang perlu disampaikan sehingga tidak bertele-tele, serta dampak positif apa yang hendak disampaikan agar bisa diterima dengan mudah tanpa terkesan menggurui. Penulis mengadaptasi strategi komunikasi Lasswell (Kotler \& Keller, 2011:286) yang sesuai dengan pemanfaatan media digital Youtube saat ini dengan adanya fitur share sehingga pesan yang ingin disampaikan melalui film pendek dokumenter bisa disebarluaskan secara masif. Selain itu, strategi komunikasi Lasswell relevan digunakan dalam 
bidang desain komunikasi visual khususnya mengangkat tema sosialisasi pesan-pesan iklan layanan masyarakat maupun pesan komersial.

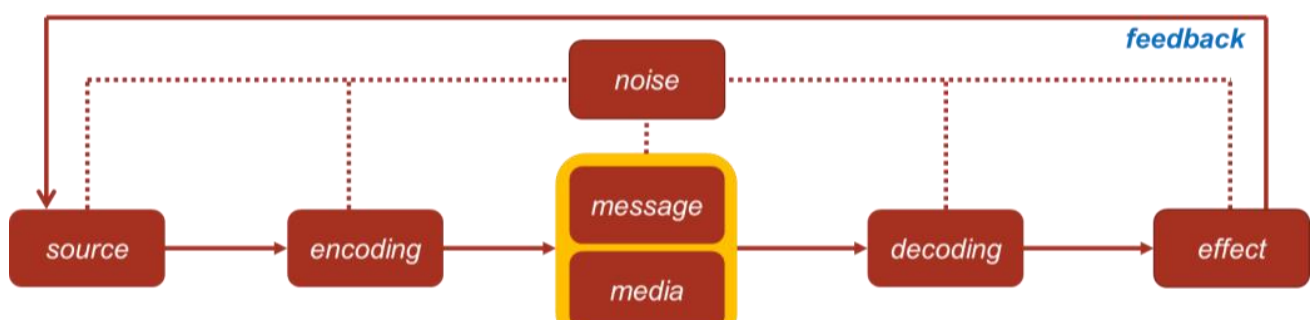

Bagan 1. Penjabaran ide film pendek dokumenter dengan pendekatan komunikasi Lasswell Sumber: Kotler \& Keller, 2011:286

Source dalam bagan di atas lebih fokus pada siapa yang menyajikan atau menyampaikan pesan pelestarian Cuora Amboinensis. Dalam konteks ini, source dipegang oleh penulis sebagai inisiator dan pembuat film pendek dokumenter.

Encoding pada bagan di atas yaitu tahap menyandikan atau mengubah ide film pendek menjadi pesan-pesan audio visual yang lugas, serius, namun santai. Melalui audio dan visual, pesan diharapkan bisa lebih efektif diterima audiens karena melibatkan dua indera aktif secara bersamaan yakni mata dan telinga. Pesan - pesan nantinya akan disajikan dalam gambar bergerak yang menyajikan objek secara to the point, sesuai realita, serta dengan teknik sinematografi dan teknik pengambilan gambar yang sesuai dengan kebutuhan. Pesan juga disajikan dengan audio yang dikemas dalam narasi dengan teknik storytelling yang diharapkan mampu memotivasi audiens.

Message di sini yaitu konten atau cerita utama yang akan disajikan dalam film pendek, yang telah dipilih oleh penulis mencakup tujuh poin yakni: pengenalan Cuora Amboinensis, penjelasan status Appendix II, habitat yang tepat dan ideal, perilaku dan cara hidup kura-kura, cara berkembang biak, 
teknik bertelur, serta penetasan telur secara alami maupun dengan bantuan manusia.

Media untuk menyajikan ketujuh informasi tersebut di atas telah dipilih yakni film pendek dokumenter yang disajikan melalui media digital Youtube, sebagai media yang sangat relevan dengan generasi milenial saat ini dan bersifat masif. Pesan akan disajikan dengan pendekatan rasional dengan narasi yang berbobot (dengan mempertimbangkan pendapat ahli / pakar kura-kura), logis, namun mudah dipahami oleh milenial. Untuk mendukung hal ini, penulis akan melibatkan orang yang berkompeten dalam hal storytelling yakni penyiar radio sehingga meskipun pesannya bersifat serius bisa dibawakan secara santai dan terpercaya.

Decoding pada bagan di atas merupakan peran audiens yakni kelompok milenial dalam menangkap dan mengartikan pesan yang nantinya disajikan dalam film pendek dokumenter. Pengalaman dan pengetahuan audiens sangat dibutuhkan untuk menerjemahkan pesan - pesan naratif yang tersaji dalam wujud audio visual.

Effect di sini yakni dampak positif yang diharapkan dengan adanya film pendek dokumenter tentang pelestarian Cuora Amboinensis. Secara umum, dampak di sini difokuskan pada tiga aspek yakni: kognitif (pengetahuan), afektif (perasaan), dan konatif (perilaku), sehingga melalui film pendek dokumenter tentang Cuora Amboinensis yang dirancang nantinya bisa memberi insight kepada milenial tentang upaya pelestarian Cuora Amboinensis yang tepat, tertarik menyimak film pendek dokumenter dengan seksama, serta termotivasi untuk turut melestarikan Cuora Amboinensis secara bersama - sama dengan milenial lainnya dengan saling mengajak dan membagikan film pendek dokumenter ini melalui fitur share.

Terakhir, hasil film pendek dokumenter dapat disinergikan dengan program-program BKSDA, meliputi: penyuluhan dan seminar seperti kelas 
konservasi bagi Kelompok EKSATLI (Edukasi kawasan konservasi satwa, tumbuhan lingkungan), event populer seperti Jakarta Pet Show, pameran hewan, reptiland, menggandeng pesohor Panji Sang Petualang (konten kreator reptile buas), serta giveaway via social media dengan syarat ikut memviralkan film pendek ini.

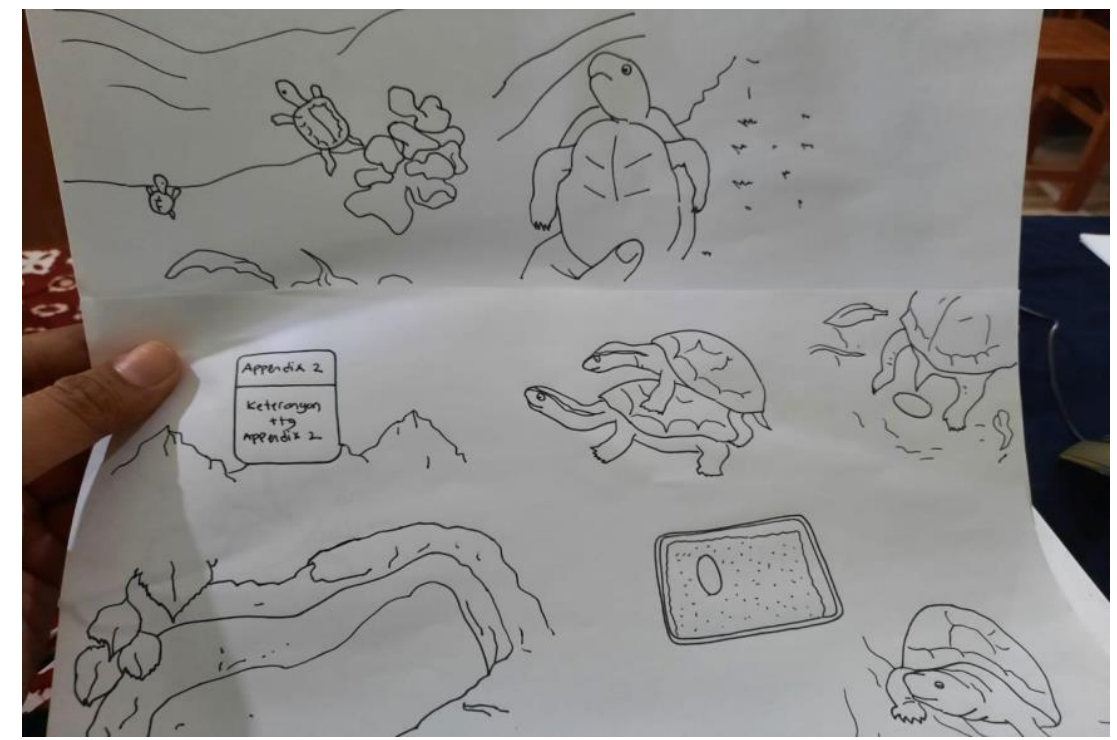

Gambar 1. Brainstorming poin utama film pendek dokumenter Sumber: Saputro dan Haryadi, 2020

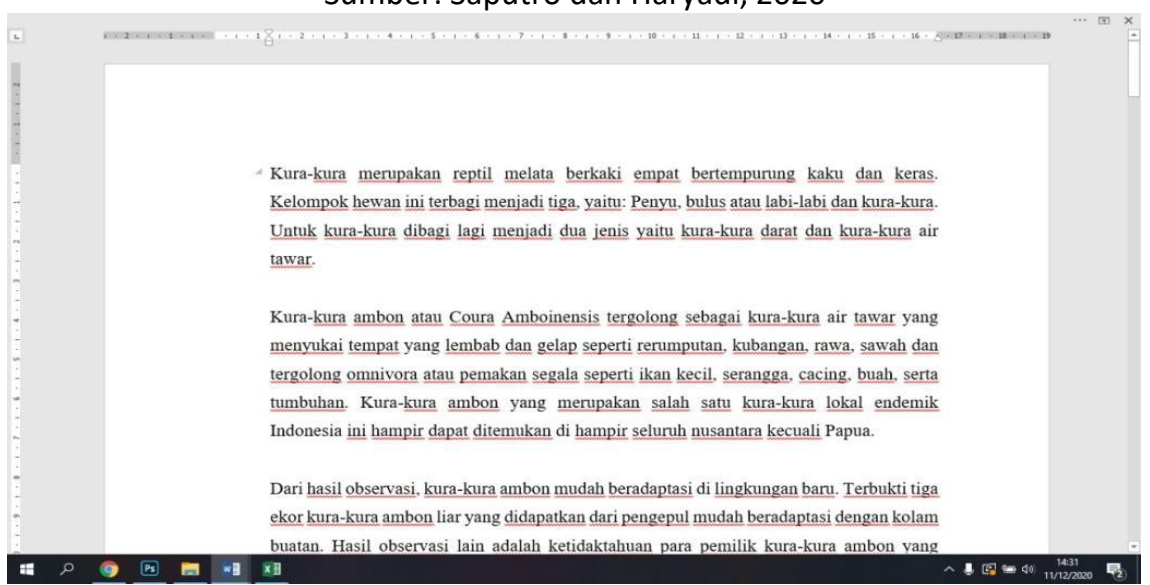

Gambar 2. Voice over untuk konten narasi dalam film pendek dokumenter Sumber: Saputro dan Haryadi, 2020 


\section{Tahap Produksi}

Pada tahap ini penulis mulai melakukan pengambilan gambar video sesuai dengan tujuh poin utama yang akan disajikan. Pengambilan gambar menggunakan kombinasi medium shot, long shot, serta close up. Medium shot digunakan untuk menampilkan rekaman perilaku dan cara hidup kura-kura, long shot digunakan saat menyajikan informasi tentang gambaran habitat kura-kura secara umum, dan close up untuk menampilkan ciri-ciri Cuora Amboinensis. Proses perekaman gambar menghasilkan 70 video yang akan digunakan untuk menyusun film pendek dokumenter. Banyaknya video ini disebabkan perekaman dilakukan dengan berbagai latar seperti kolam, daratan pasir, indoor, saat kondisi hujan, dan sebagainya.

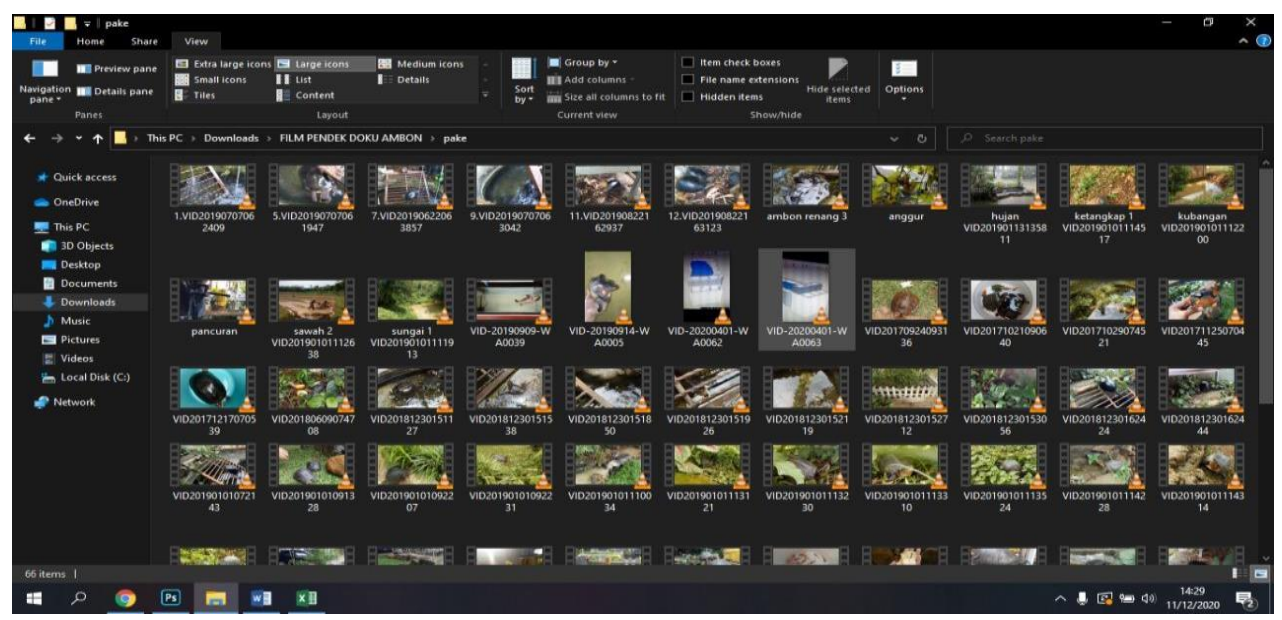

Gambar 3. Video hasil rekaman sesuai dengan konten utama yang akan disajikan Sumber: Saputro dan Haryadi, 2020

Langkah berikutnya yaitu melakukan perekaman suara untuk konten narasi dalam film pendek dokumenter. Pada bagian ini, penulis melibatkan Eka Kurniawan, penyiar radio dari Gajahmada FM. Voice over disesuaikan dengan target audience yaitu remaja pria dengan gaya bercerita santai, informatif, dan berbahasa Indonesia gaul dengan tempo adante (sekitar 6876 ketuk per menit). Pihak lain yang memiliki kemampuan storytelling yang 
komunikatif dan mampu mengatur tempo dan intonasi penceritaan secara tepat. Narasi ini difungsikan untuk mendukung penyajian video agar informasi yang disampaikan jelas dan tidak ambigu.

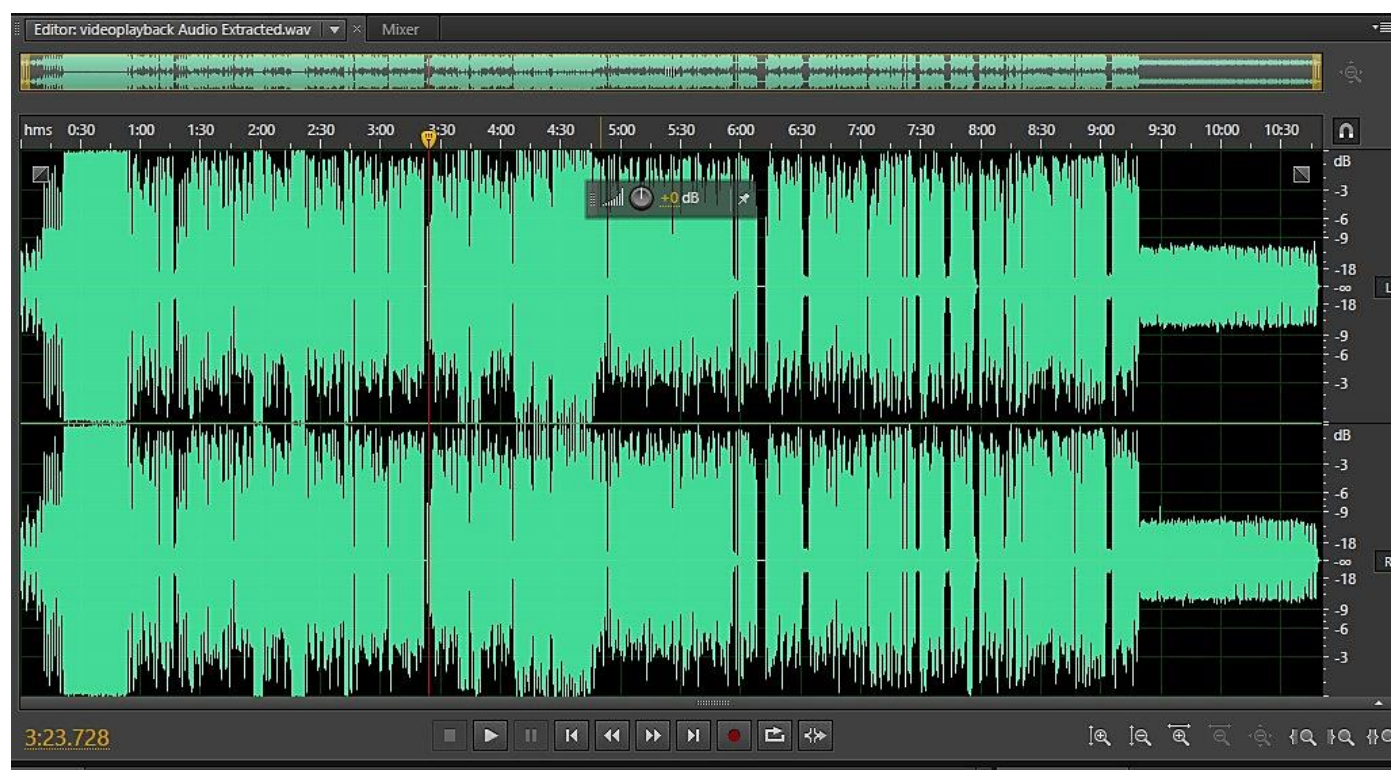

Gambar 4. Hasil perekaman voice over sebagai narasi Sumber: Saputro dan Haryadi, 2020

\section{Tahap Pascaproduksi}

Pada tahap ini, penulis melakukan arrangement video dan voice over menggunakan Adobe Premiere Pro. Pemilihan software ini didasarkan pada kemampuan dalam mengolah dan menggabungkan berbagai file yang sifatnya kompleks. Selain video dan audio, penulis juga menyisipkan still image, motion graphic, serta teks untuk lebih memperjelas pesan yang ingin disampaikan dipadu dengan beberapa jenis cutting seperti straight cut, jump cut, match cut, dan contrast cut. Penggabungan semua elemen ini juga untuk aspek estetika agar penonton tertarik dan menikmati tayangan film pendek dokumenter yang dihasilkan. 


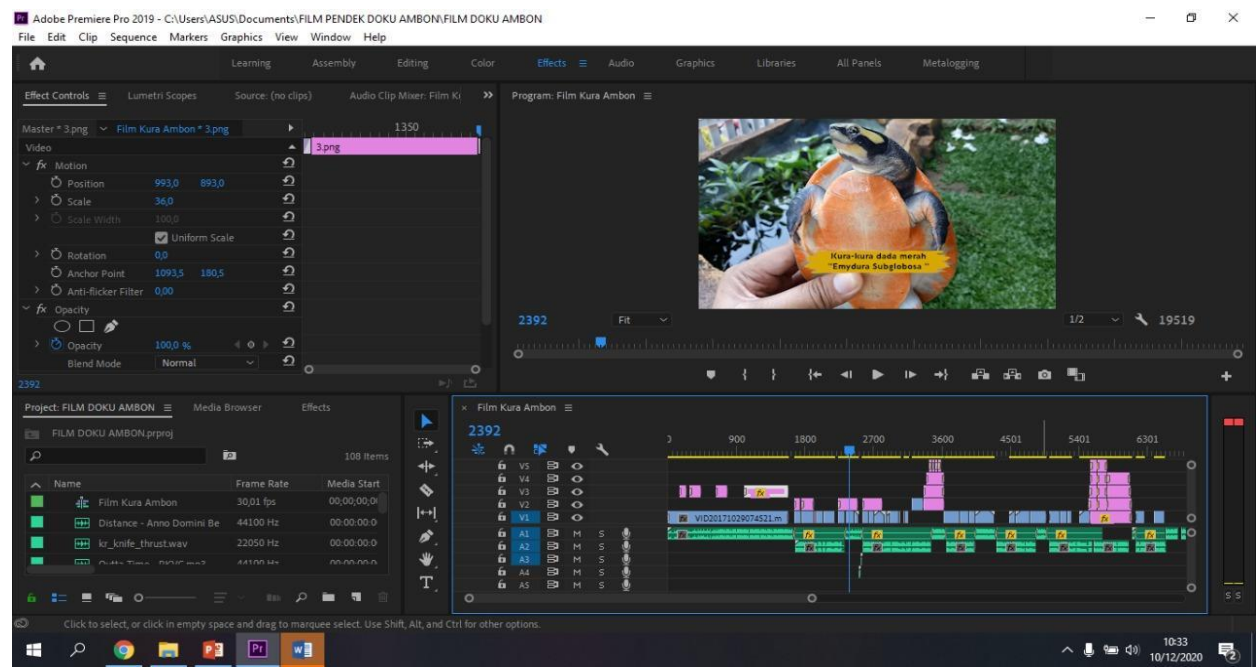

Gambar 5. Editing dan compositing berbagai video yang diperlukan Sumber: Saputro dan Haryadi, 2020

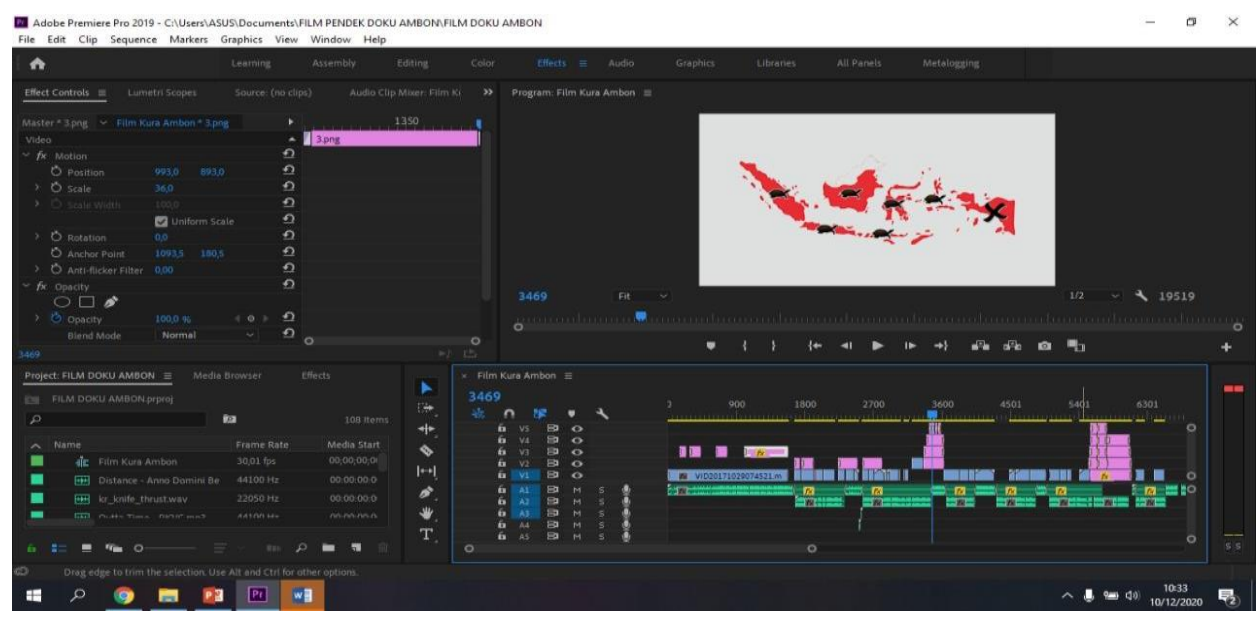

Gambar 6. Penambahan still image dan motion graphic Sumber: Saputro dan Haryadi, 2020

Setelah proses editing dan compositing, berikutnya yaitu rendering yang hasilnya akan ditayangkan di channel youtube BKSDA. Pemilihan youtube sebagai platform penayangan film pendek dokumenter karena potensial, mudah diakses oleh siapa saja, dimana saja, serta kapan saja sehingga tepat sebagai cara untuk mengedukasi pelestarian dan pengembangbiakan Cuora Amboinensis. 


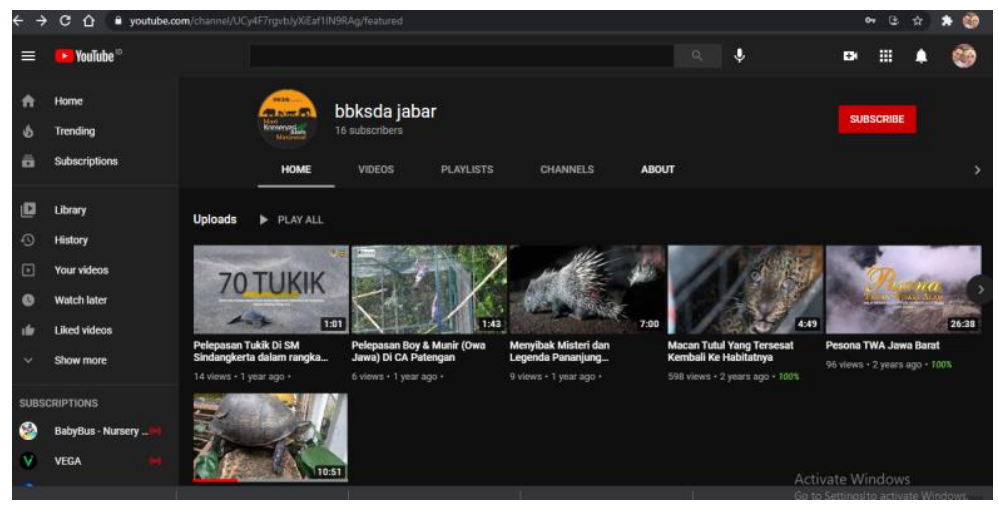

Gambar 7. Penayangan film pendek dokumenter di youtube Sumber: Saputro dan Haryadi, 2020
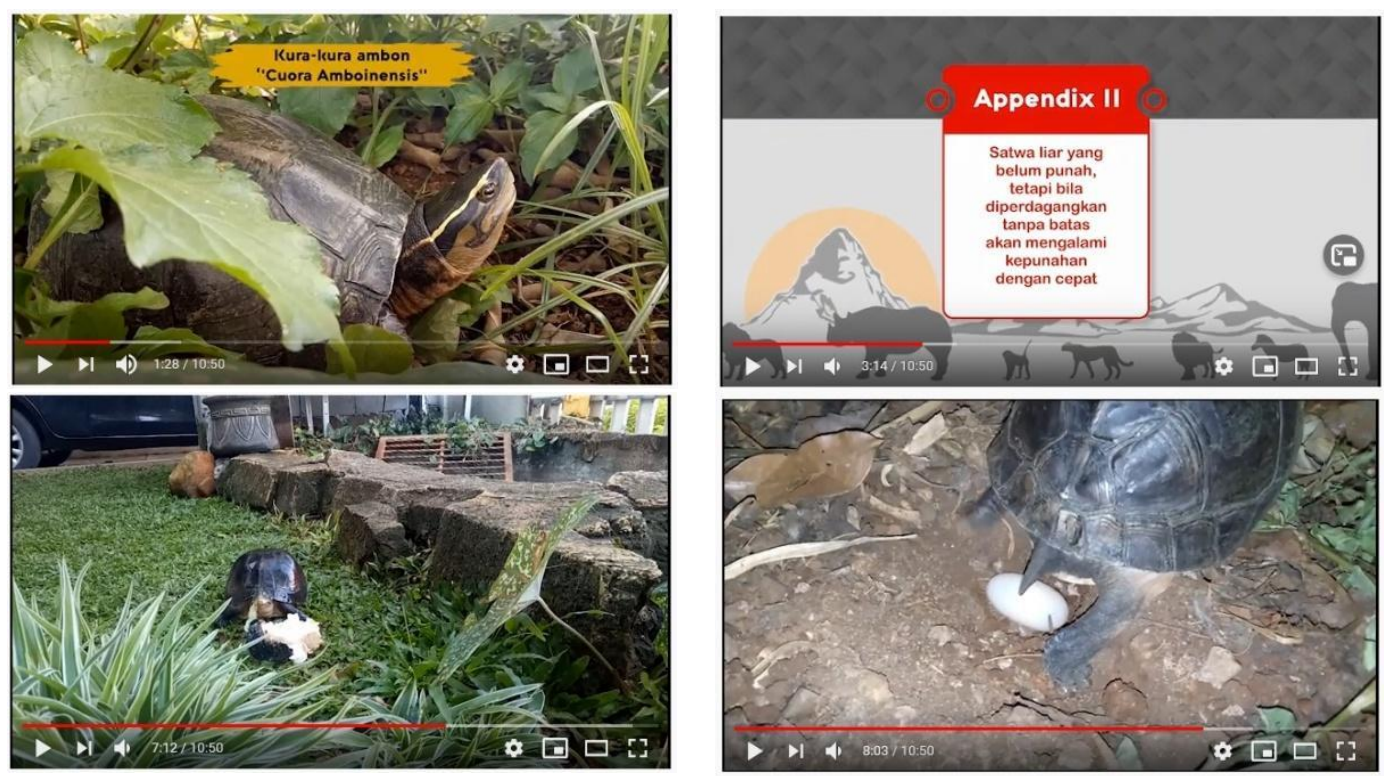

Gambar 8. Screenshot film pendek dokumenter Cuora Amboinensis Sumber: Saputro dan Haryadi, 2020

\section{KESIMPULAN}

Maraknya kepunahan hewan liar yang terjadi di Indonesia, salah satunya kura-kura Cuora Amboinensis akibat eksploitasi yang berlebihan serta pengembangbiakan yang tidak tepat telah mendorong penelitian ini dilakukan yakni bagaimana mengedukasi masyarakat untuk melestarikan hewan tersebut dengan media yang tepat. Melalui penelitian ini, edukasi pelestarian 
Cuora Amboinensis telah dirumuskan dan menghasilkan solusi yakni media edukasi berbasis audio visual dalam bentuk film pendek dokumenter. Hal ini didasarkan pertimbangan bahwa film dokumenter mampu menyajikan realita yang dikemas melalui video, suara, dan teks. Penyajian audio visual mendorong indera penglihatan, pendengaran, dan pikiran menjadi aktif, sehingga banyak pesan yang terserap dengan baik dan jelas. Dengan durasi 10 menit, hal ini sesuai dengan waktu rata-yang mampu dilakukan audiens untuk tetap fokus dalam menangkap pesan berbasis audio visual, yakni antara 1016 menit. Hal ini juga ditunjang dengan kelebihan platform Youtube yang mudah diakses siapapun, kapanpun, dan di mana pun, sehingga pesan-pesan dalam film pendek dokumenter ini bisa cepat menyebar dan bermanfaat.

Hasil penelitian ini merupakan salah satu bentuk untuk berperan serta dalam mengembangkan dan mengoptimalkan fungsi desain komunikasi visual sebagai media edukasi yang multidisiplin. Melalui media ini, para pihak yang bertanggung jawab terhadap kelestarian hewan termasuk masyarakat bisa mempraktikkan pesan-pesan yang tersaji di dalamnya. Tidak dipungkiri bahwa penelitian ini masih memiliki kekurangan, salah satunya yaitu terbatasnya narasumber yang bisa dijadikan sebagai informan dan terbatasnya aktivitas dalam perekaman video akibat pandemi Covid-19, yang berdampak pada informasi yang tersaji masih belum lengkap. Sehingga, penelitian ini bisa dikembangkan lebih jauh dengan menyajikan media edukasi yang berisi informasi tentang pelestarian hewan liar secara lebih lengkap dan detail, khususnya Cuora Amboinensis, umumnya hewan liar lain yang perlu mendapat perhatian. Penelitian ini juga diharapkan bisa menggugah dan mendorong peneliti lain untuk mengeksplorasi fungsi media komunikasi visual dalam upaya pelestarian hewan liar Indonesia yang tidak hanya berwujud film pendek dokumenter, tetapi bisa melalui media lain yang sesuai dengan target audiens. 


\section{PERNYATAAN PENGHARGAAN}

Penulis mengucapkan terima kasih kepada Universitas Dian Nuswantoro yang telah mendukung penelitian ini, serta kepada Bapak Surya Margahayu sebagai narasumber yang bersedia membagikan pengetahuan, pengalaman, serta informasi-informasi penting yang dibutuhkan dalam pelestarian dan pengembangbiakan Cuora Amboinensis dengan metode yang tepat dan tepat sebagai topik utama dalam penelitian ini.

\section{DAFTAR PUSTAKA}

Creswell, J. 1998. Qualitative Inquiry and Research Design. London: Sage Publications

Faiqah, F., Nadjib, M., dan Amir, A. S. 2016. Youtube Sebagai Sarana Komunikasi Bagi Komunitas Makassarvidgram. Jurnal Komunikasi KAREBA, Vol. 5, No. 2, p: $259-272$

Fajar, T. 2019. Studi Nielsen: Pemirsa Indonesia Habiskan 5 jam Nonton TV, 3 Jam Berselancar di Internet. Diakses dari: https://economy.okezone.com/read/2019/03/05/320/2025987/studinielsen-pemirsa-indonesia-habiskan-5-jam-nonton-tv-3-jam-berselancar-diinternet?page $=1$, pada: 14 Oktober 2020, pukul 20.10 wib

Saputro, G. E., dan Haryadi, T. 2018. Edukasi Kampanye Anti Hoax Melalui Komik Strip. Jurnal DEMANDIA, Vol.3 No.2, p: 94-111

Kapriani, D. R., dan Lubis, D. P. 2014. Efektivitas Media Sosial Untuk Gerakan Sosial Pelestarian Lingkungan. Sodality: Jurnal Sosiologi Pedesaan, Vol. 2, No. 3, p: $160-170$.

Kotler, P. dan Keller K. L. 2011. Manajemen Pemasaran. Malang: Bayumedia

Mabruri, A. 2013. Manajemen Produksi Program Acara Televisi Format Acara Drama. Jakarta: PT Grasindo

Maryani, I., Ruyani, A., Karyadi, B., dan Suhartoyo, H. 2018. Studi Pertumbuhan Awal Kuya Batok (Cuoro Ambonensis) di Kolam Kehutanan UNIB serta 
Implementasinya sebagai Bahan Ajar Zoologi Vertebrata. Jurnal Pendipa, Vol. 2 No. 3, p:200-205

Megumi, S. 2020. Kura-Kura Ambon Hidup di Berbagai Tipe Wilayah. Diakses dari: https://www.greeners.co/flora-fauna/kura-kura-ambon-hidup-diberbagai-tipe-wilayah/, pada: 15 april 2020 pukul 13.55 wib

Nielsen. 2016. Video on Demand. Diakses dari: https://www.nielsen.com/wpcontent/uploads/sites/3/2019/04/global-video-on-demand-report-mar2016.pdf, pada: 6 Desember 2020 pukul 10.40 wib

Perkasa, H. dan Sayatman, S. 2015. Perancangan Film Dokumenter - Kawasan Purbakala Gunung Penanggungan. Jurnal Sains dan Seni, Vol.5 No.2, p: 355361

Rahmad, R. 2020. Film Pohon 2020, Penghargaan Untuk Sineas Muda Peduli Lingkungan. Diakses dari: https://www.mongabay.co.id/2020/12/01/filmpohon-2020-penghargaan-untuk-sineas-muda-peduli-lingkungan/, pada: 6 Desember 2020 pukul 13.25 wib

Rahmawan, D., Mahameruaji, J.N., dan Alnashava, P. 2018. Potensi Youtube Sebagai Media Edukasi Bagi Anak Muda. Jurnal Edulib, Vol. 8, No.8, p: 8198.

Resmadi, I., Bastari, R.P., dan Prahara, G.A. 2020. Analisis Strategi Media Komunikasi Visual Label Rekaman Independen Di Era Digital: Studi Kasus Strategi Komunikasi Dari Sun Eater Records. Jurnal DEMANDIA, Vol.5 No.2, p: $212-232$

Sambo, M. 2019. Media relations Kontemporer: teori dan praktik. Jakarta: Kencana

Septian, R. 2017. Penelitian: Permintaan Tinggi, Kura-kura Marak Diperdagangkan. Diakses dari: https://www.mongabay.co.id/2017/06/19/penelitian-permintaantinggi-kura-kura-marak-diperdagangkan/, pada: 14 april 2020 pukul 11.25 wib

Tabrani, P. 2005. Bahasa Rupa. Bandung: Kelir

Topatimasang, R., Rahardjo, T., dan Fakih, M. 2015. Pendidikan Popular: Membangun Kesadaran Kritis. Yogyakarta: INSISTPress 